\title{
Thermal structure of the atmospheric boundary layer over the South African Mpumalanga Highveld
}

\author{
Stefan Becker* \\ Department of Geography and Urban Planning, University of Wisconsin Oshkosh, 800 Algoma Boulevard, Oshkosh, \\ Wisconsin 54901, USA
}

\begin{abstract}
This study deals with the parametrisation of the vertical thermal structure of the atmospheric boundary layer up to $100 \mathrm{~m}$ above ground level over the industrial Mpumalanga Highveld in South Africa. Potential air temperatures were calculated by similarity theory based algorithms. The results were unsatisfactory for stable and unstable conditions in comparison to the measured data of a $96 \mathrm{~m}$ tower. A higher accuracy was achieved with algorithms constructed by subjecting the measured data to multiple regression analysis. Potential air temperatures at various levels up to $96 \mathrm{~m}$ above ground level were calculated with average errors of $0.82^{\circ} \mathrm{C}$ for stable conditions, $0.63^{\circ} \mathrm{C}$ for unstable early-morning and late-afternoon conditions and $0.37^{\circ} \mathrm{C}$ for unstable daytime conditions. The accuracy was sufficient to assess the thermal atmospheric stability of the boundary layer up to $100 \mathrm{~m}$ above ground level.
\end{abstract}

KEY WORDS: Thermal atmospheric stability · Atmospheric boundary layer • Vertical potential air-temperature lapse rate

\section{INTRODUCTION}

The thermal structure of the atmosphere is described by the lapse rate of the temperature, which influences the ability of the atmosphere to promote or inhibit vertical motion of air (Preston-Whyte \& Tyson 1993). Knowledge of the vertical thermal structure of the boundary layer is imperative for many purposes, e.g. the modelling of air pollution dispersion. However, continuous data are usually not available to determine this, and therefore numerous models exist for the modelling of thermal stability or heights of inversion layers from ground-based data.

The South African Mpumalanga Highveld region contains large coal fields and power stations which generate almost half of Africa's electricity (Eskom 1994, Held et al. 1996). Considerable amounts of air pollution are also generated and dispersed in the atmosphere. Knowledge of the thermal structure over this region is imperative to assess the air pollution dispersion and model the near-ground air pollution levels. The Highveld is characterised by a flat surface with minor topographical features or variations in altitude. Therefore, it can be assumed that the radius of validity is rather large, and the results of the calculations at one specific location can be transferred to large parts of the entire region.

Climatic data for the calculation of boundary-layer parameters were measured at a $96 \mathrm{~m}$ mast located in the vicinity of a power station at Kendal (Fig. 1). Air temperatures and wind data were measured at 1, 2, 5, $10,20,40,65$ and $96 \mathrm{~m}$ levels and 6 data sets $\mathrm{h}^{-1}$ were available from July 1993 to August 1994. Damage by lightning caused major data gaps from January to April 1994; however, there were still more than 40000 data sets available for analysis.

\section{CALCULATION OF THE VERTICAL THERMAL STRUCTURE}

Calculation of boundary-layer parameters refers mainly to similarity theory, which is based on Monin \& Obukhov (1954). The calculation of the vertical profile of air temperatures according to similarity theory is based on the algorithms which are presented in, for example, Jacobsen (1999), Pichler (1997) and Roedel (2000). 


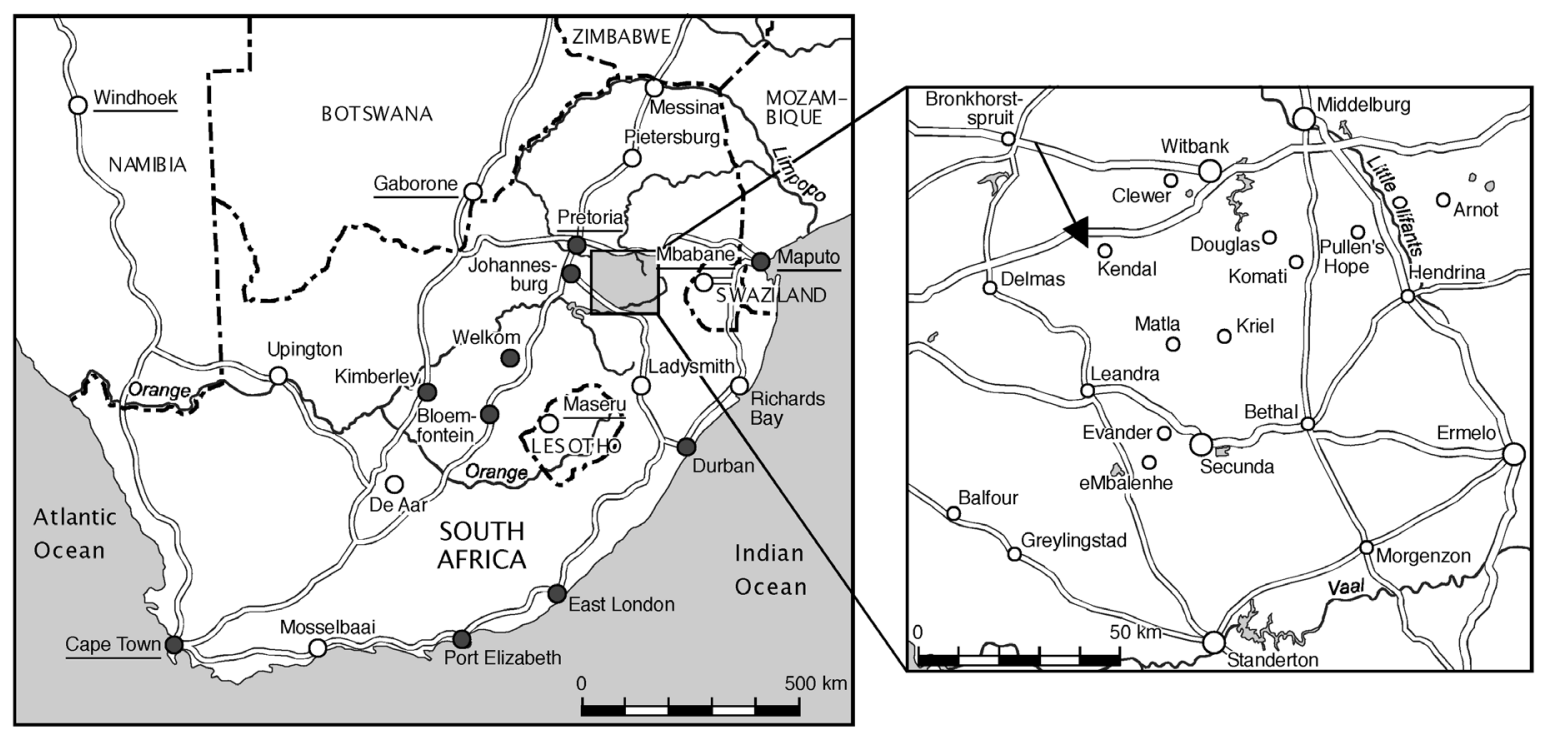

Fig. 1. Location of the research site: the South African Mpumalanga Highveld

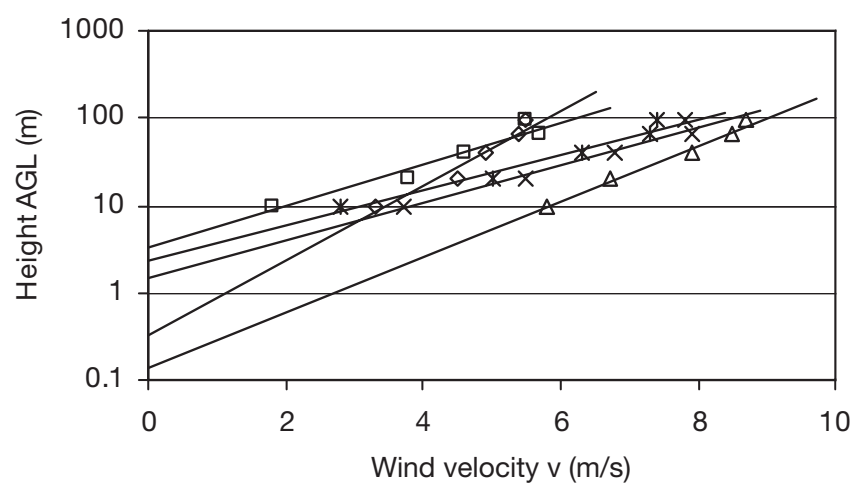

Fig. 2. Extrapolation of the surface roughness length, $z_{0}$ : examples at neutral conditions

The required surface roughness length for momentum, $z_{0}$, which can be extracted from tables should be within the range between 0.1 and 0.5 (long grass to savannah) (e.g. Jacobsen 1999, Oke 1987). Extrapolation by exponential functions under neutral conditions yields values between 0.2 and $5 \mathrm{~m}$ (Fig. 2). The heights above ground level will be referred to as height AGL in the following discussion.

The roughness length was estimated empirically by iteration. Wind data for the different heights under near-neutral conditions (Richardson number, $|R i|<$ 0.03 or difference between potential temperatures at 1.2 and $10 \mathrm{~m}$ levels $<0.3^{\circ} \mathrm{C}$ ) were calculated by the logarithmic wind law and compared to the measured values. The differences between calculated and measured values depending on $z_{0}$ values in the range from
0.03 to $0.8 \mathrm{~m}$ can be seen from Fig. 3. The bar highlights the $z_{0}$ range of minimum wind errors.

It becomes apparent that the roughness length of approximately 0.3 provides the best results and the absolute deviations increase with height above ground. The simple logarithmic law obviously requires some adaptation to calculate wind speeds on the Highveld under neutral conditions. The boundary layer parameters $u^{*}, \theta^{*}$ and $L$ were calculated by an iterative and a non-iterative approach (Jacobsen 1999, Louis 1979). Fig. 4 shows that the results of both approaches yield almost identical results. Minor variations are apparent for small $u^{*}$ values, which could be due to the simplification within this approach. The results of the iterative approach were used for the following calculations.

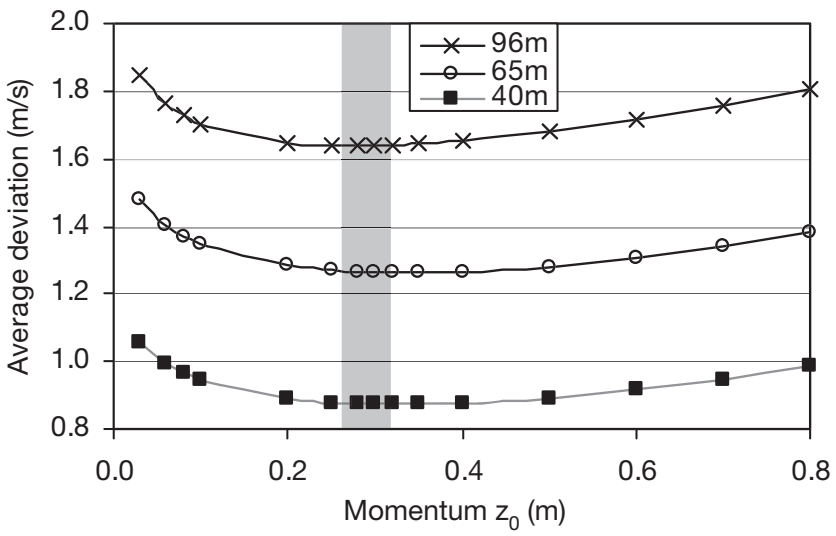

Fig. 3. Mean difference between calculated and measured wind speeds at different heights under neutral conditions 

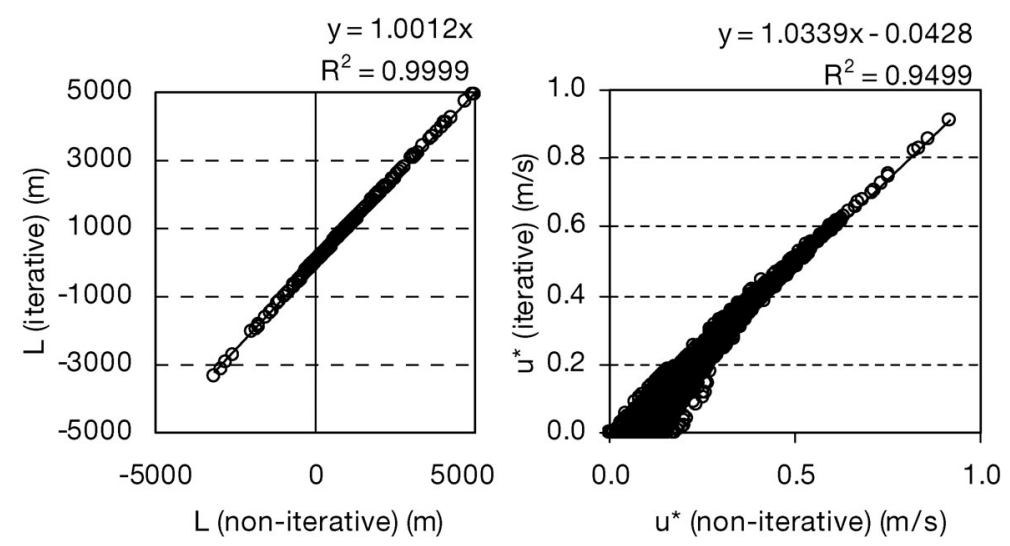

Fig. 4. Correlation between the results of the iterative and the noniterative approach to calculate (a) the Monin-Obukhov length $(L)$ and (b) friction velocity $\left(u^{*}\right)$

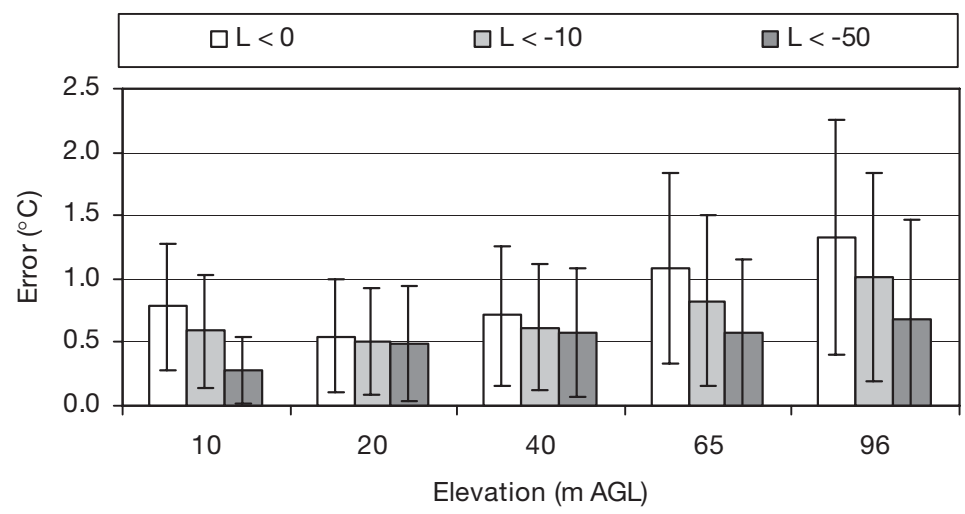

Fig. 5. Mean errors and standard deviation of errors of potential air temperature calculations during unstable conditions

\subsection{Calculation of potential air temperatures during unstable conditions}

The calculation of the potential temperatures at different heights based on the algorithms derived from the similarity theory were compared to the measured data. The following accuracies were detected for all cases of instability ( $L<0$ : 18216 data sets, $L<-10$ : 9460 data sets and $L<-50: 4275$ data sets) (Fig. 5).

Potential air temperature calculations which are based on the described model are less accurate at higher elevations. Average errors for $96 \mathrm{~m}$ are partly more than twice the magnitude of errors for $20 \mathrm{~m}$. The differentiation between the 3 cases reveals furthermore, that the model shows its best performance for weaker instabilities, whereas strongly unstable conditions (small negative $L$ ) are associated with less accurate prediction of potential air temperatures. The question of whether the calculated potential temperatures will be acceptable for the calculation of thermal stability can only be answered after examining the consequences on the lapse rates. The comparison of lapse rates based on measured and calculated data reveals that unstable conditions between 10 and $20 \mathrm{~m}$ generally correspond. However, higher degrees of instability which occur usually during strong noontime convection, are seriously underestimated by the model (average errors for $96 \mathrm{~m}$ potential air temperatures are in excess of $1.3^{\circ} \mathrm{C}$ ). This statement is also valid based on the whole data set, where the average potential air temperature difference of the measured data is considerably lower (average $0.58^{\circ} \mathrm{C}$, standard deviation 0.47 ) than the one which is based on the calculated values. The model seems to overestimate the temperature decline in the upper layers. Furthermore, the strong variation of lapse rates even at the upper levels is not recognised by the model calculations.

\subsection{Calculation of potential air temperatures during stable conditions}

25553 cases with stable atmospheric layering $(L>0)$ were available for the comparison between measured and calculated potential temperatures. The calculation of potential temperatures according to the algorithms proved to be entirely out of the range for cases during strong stability (small positive $L$ ). Average errors of potential air temperatures for $96 \mathrm{~m}$ AGL exceeded $5^{\circ} \mathrm{C}$ for $L<100$. Useful results could only be obtained for weakly stable conditions with $L$ approximately larger than 100 (3542 valid cases). The increase in average errors with height is clearly visible in Fig. 6.

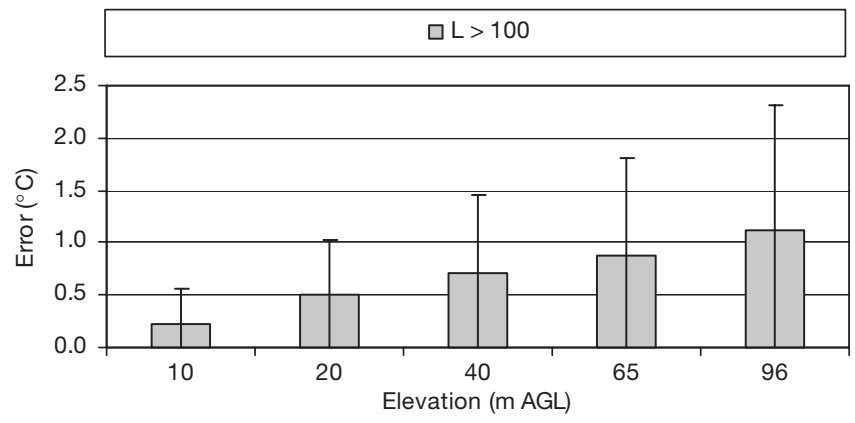

Fig. 6. Mean errors and standard deviation of errors of potential air temperature calculations during weakly stable conditions $(L>100)$ 

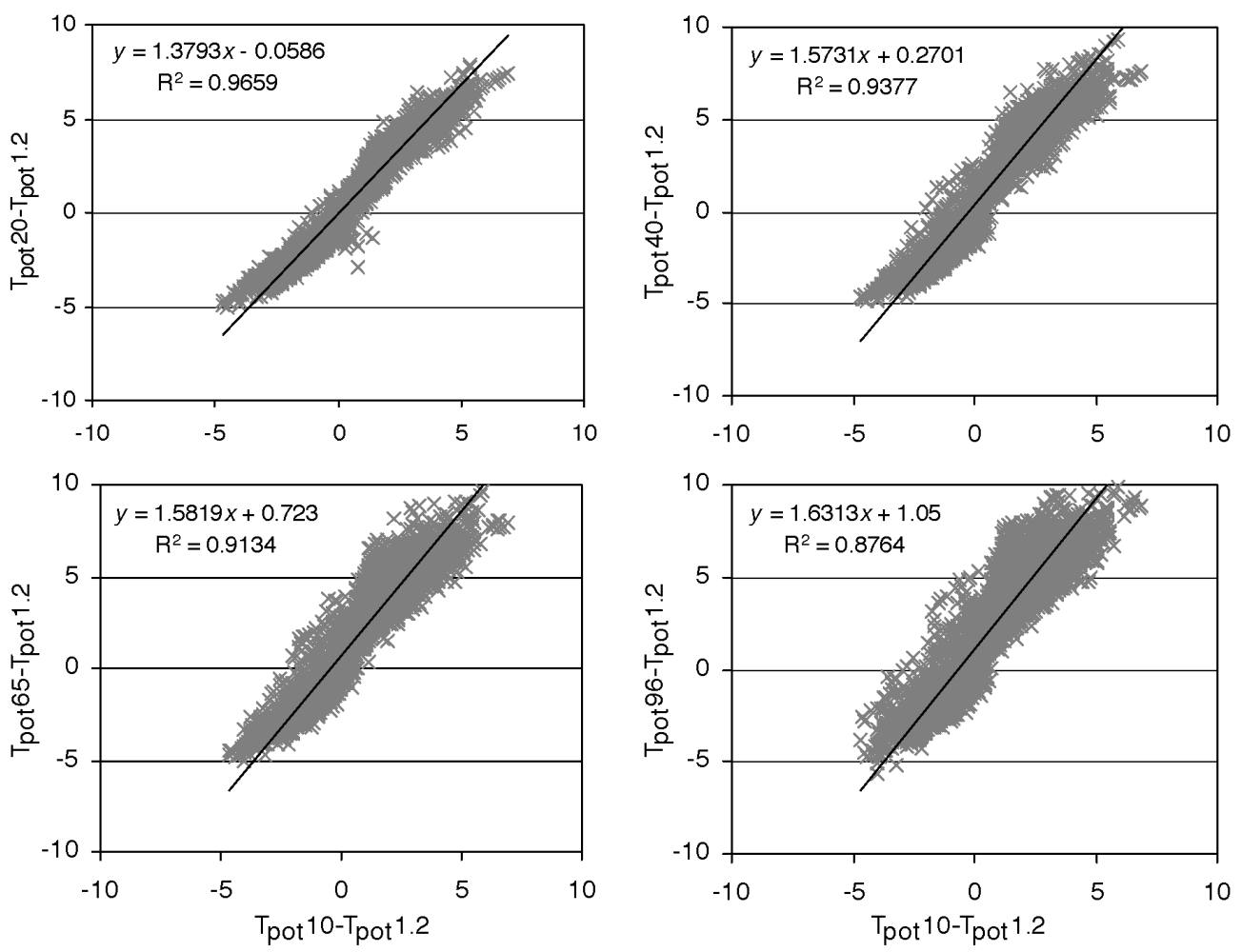

Fig. 7. Correlation between the measured potential air-temperature differences at various levels

\subsection{Evaluation of the results}

The average errors of the calculation of vertical potential air temperature profiles during stable conditions are generally $>1^{\circ} \mathrm{C}$ at heights of $\sim 100 \mathrm{~m} \mathrm{AGL}$. Furthermore, this method fails to discern between stable and unstable layers within the profile. It is therefore not suitable to reproduce the characteristics of the thermal atmospheric layering within the boundary layer. The reason for this result could be the inaccuracy which comes along with the calculation of the Monin-Obukhov length or the relevant scaling parameters. In addition to that it might be the special situation of the Highveld, with its elevation of more than $1600 \mathrm{~m}$ above sea level and other climatological particularities, which causes many uncertainties in the application of the algorithms.

Table 1. Mean deviation $\left({ }^{\circ} \mathrm{C}\right)$ between measured and calculated potential air temperatures based on the linear regression functions

\begin{tabular}{|lccc|}
\hline Difference & $\begin{array}{c}\text { All } \\
\text { data }\end{array}$ & $\begin{array}{c}\text { Stability } \\
(25739 \text { cases })\end{array}$ & $\begin{array}{c}\text { Instability } \\
(18100 \text { cases })\end{array}$ \\
\hline $1.2-20 \mathrm{~m}$ & 0.43 & 0.35 & 0.55 \\
$1.2-40 \mathrm{~m}$ & 0.64 & 0.47 & 0.75 \\
$1.2-65 \mathrm{~m}$ & 0.77 & 0.76 & 0.77 \\
$1.2-96 \mathrm{~m}$ & 0.95 & 0.96 & 0.95 \\
\hline
\end{tabular}

\section{VERTICAL PROFILE OF POTENTIAL AIR TEMPERATURES}

\subsection{Undifferentiated linear regression model}

Following observations of the previous test analyses, it appeared to be meaningful to correlate $1.2-10 \mathrm{~m}$ potential air temperature differences with $1.2-20 \mathrm{~m}$, 1.2-40 m, 1.2-m and 1.2-96 m differences and establish a relationship with height AGL. Fig. 7 confirms the strong correlations between the differences based on 10000 data sets.

The average differences between the measured values and the ones which were calculated by the linear functions (Fig. 7) can be seen in Table 1. The accuracy of the calculation decreases with height. Differences during stable atmospheric layering can be calculated up to $40 \mathrm{~m}$ AGL with an average error $<0.5^{\circ} \mathrm{C}$; however, larger errors are noted for the higher regions. The accuracy achieved by this undifferentiated multiple-regression model already exceeds that for the similarity theory based approach. Axis intercepts and slopes of the regression lines can be correlated closely to the relevant height by logarithmic functions (Fig. 8). This step enables the definition of a continuous function which relates the difference to the height. 


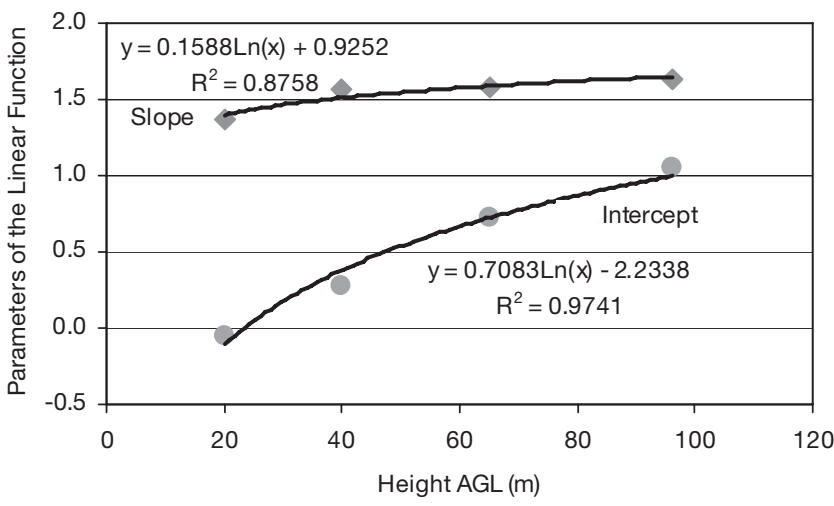

Fig. 8. Parameters of the linear functions for the continuous calculation of potential air-temperature differences

The difference from bottom level $(1.2 \mathrm{~m})$ to the height (h) can therefore be calculated using

$$
\Gamma_{\theta(1.2-h)}=(0.158 \ln (h)+0.925) \Gamma_{\theta(1.2-10)}+(0.708 \ln (h)-2.23)
$$

where $h$ is height AGL (m) and $\Gamma_{\theta(1.2-h)}$ and $\Gamma_{\theta(1.2-10)}$ are the differences of potential air temperatures between $1.2 \mathrm{~m}$ and $h$ and between 1.2 and $10 \mathrm{~m}$, respectively.

\subsection{Differentiated multiple linear regression model}

A higher grade of accuracy can be achieved by multiple linear regression after differentiating stable and unstable atmospheric layering near the ground.

\subsubsection{Stable atmospheric layering near the ground}

Stable atmospheric layering for this purpose is defined by positive potential air temperature differences between the $1.2 \mathrm{~m}$ and $10 \mathrm{~m}$ levels $\left(\theta_{10}-\theta_{1.2}>0\right)$. The multiple regression analysis with implementation of $\theta_{1.2}$ (potential air temperature at $1.2 \mathrm{~m}$ height) and $\Gamma_{\theta(1.2-10)}$ yields, e.g. for $96 \mathrm{~m}$

$$
\Gamma_{\theta(1.2-96)}=1.387 \Gamma_{\theta(1.2-10)}-0.0909 \theta_{1.2}+27.368
$$

The corresponding accuracies can be seen in Table 2 .

The separate consideration of stable cases under implementation of only 2 independent variables already leads to an improvement of the calculations. Differences between measured and calculated differences decrease slightly according to the relevant averages and quantiles. Table 3 shows cross tables of correlation coefficients for potential air temperature differences between the 1.2 and $96 \mathrm{~m}$ levels based on the parameters considered to be relevant for the multiple regression. The strongest influencing factors for differences between the bottom level and the
Table 2. Accuracy of difference calculations based on mul-

\begin{tabular}{|c|c|c|c|c|c|}
\hline & \multicolumn{2}{|c|}{ Mean } & \multicolumn{2}{|c|}{ Quantile $\left({ }^{\circ} \mathrm{C}\right)$} & \multirow{2}{*}{$\begin{array}{c}\text { Median } \\
\left({ }^{\circ} \mathrm{C}\right)\end{array}$} \\
\hline & $\left({ }^{\circ} \mathrm{C}\right)$ & $(\%)$ & $90 \%$ & $75 \%$ & \\
\hline$\Delta \Gamma_{\theta(1.2-96)}$ & 0.89 & 26 & 1.80 & 1.24 & 0.74 \\
\hline
\end{tabular}
tiple regression for stable layering

Table 3. Pearson correlation coefficient for various factors during stable atmospheric layering. $\Gamma_{\theta(1.2-96)}$ : difference of potential air temperatures between $1.2 \mathrm{~m}$ and $96 \mathrm{~m}(\mathrm{~K}) ; \theta_{1.2}$ : potential air temperature at $1.2 \mathrm{~m}$ AGL $(\mathrm{K}) ; \theta^{*}$ : potential temperature scale; $V_{10}$ : wind speed at $10 \mathrm{~m}$ height $\left(\mathrm{m} \mathrm{s}^{-1}\right) ; \Gamma_{\theta(1.2-10)}$ : difference of potential air temperatures between 1.2 and $10 \mathrm{~m}(\mathrm{~K})$

\begin{tabular}{|lrrrrr|}
\hline & $\Gamma_{\theta(1.2-96)}$ & $\theta_{1.2}$ & $\theta^{*}$ & $V_{10}$ & $\Gamma_{\theta(1.2-10)}$ \\
\hline$\Gamma_{\theta(1.2-96)}$ & 1.000 & -0.453 & 0.539 & -0.420 & 0.812 \\
$\theta_{1.2}$ & & 1.000 & 0.200 & 0.036 & -0.294 \\
$\theta^{*}$ & & & 1.000 & -0.378 & 0.631 \\
$V_{10}$ & & & & 1.000 & -0.471 \\
$\Gamma_{\theta(1.2-10)}$ & & & & & 1.000 \\
\hline
\end{tabular}

other levels are obviously the differences between the lowest levels $\left(\Gamma_{\theta(1.2-10)}\right)$; however, the variance of the other variables also seems to be more or less strongly related to the variance of the sought-after differences.

Multiple-regression analysis with implementation of all the variables in Table 3 yields

$$
\begin{aligned}
& \Gamma_{\theta(1.2-20)}=1.101 \Gamma_{\theta(1.2-10)}-0.0512 v_{10}+0.618 \theta^{*}-0.049 \theta_{1.2}+14.279 \\
& \Gamma_{\theta(1.2-40)}=1.097 \Gamma_{\theta(1.2-10)}-0.0747 v_{10}+0.998 \theta^{*}-0.082 \theta_{1.2}+24.110 \\
& \Gamma_{\theta(1.2-65)}=0.998 \Gamma_{\theta(1.2-10)}-0.0865 v_{10}+1.195 \theta^{*}-0.107 \theta_{1.2}+31.671 \\
& \Gamma_{\theta(1.2-96)}=0.954 \Gamma_{\theta(1.2-10)}-0.1040 v_{10}+1.325 \theta^{*}-0.137 \theta_{1.2}+40.501
\end{aligned}
$$

The inclusion of these variables into the multiple linear regression leads to a further improvement of the results, as can be seen from $\Gamma_{\theta(1.2-96)}$ in Table 4.

Fig. 9 shows again that the vertical profile of multiple regression factors can be described by continuous functions.

Table 4. Mean deviation of measured and calculated potential air temperature differences based on multiple linear regression functions for stable atmospheric layering near the ground

\begin{tabular}{|cccccc|}
\hline & \multicolumn{2}{c}{ Mean } & \multicolumn{2}{c|}{ Quantile $\left({ }^{\circ} \mathrm{C}\right)$} & Median \\
& $\left({ }^{\circ} \mathrm{C}\right)$ & $(\%)$ & $90 \%$ & $75 \%$ & $\left({ }^{\circ} \mathrm{C}\right)$ \\
\hline$\Gamma_{\theta(1.2-20)}$ & 0.31 & 15 & 0.66 & 0.40 & 0.22 \\
$\Gamma_{\theta(1.2-40)}$ & 0.52 & 20 & 1.11 & 0.70 & 0.39 \\
$\Gamma_{\theta(1.2-65)}$ & 0.68 & 22 & 1.37 & 0.95 & 0.56 \\
$\Gamma_{\theta(1.2-96)}$ & 0.82 & 24 & 1.68 & 1.14 & 0.67 \\
\hline
\end{tabular}



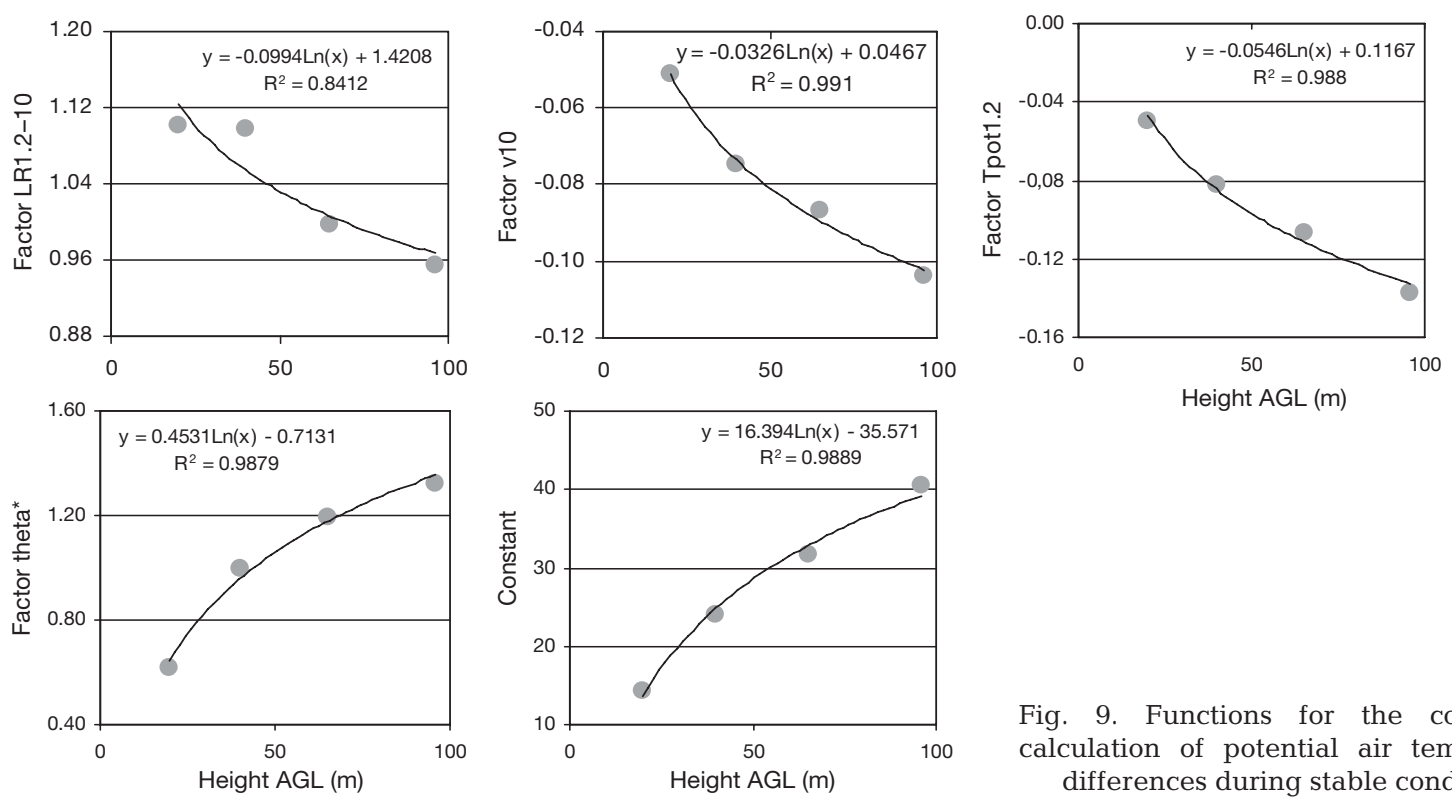

Fig. 9. Functions for the continuous calculation of potential air temperature differences during stable conditions

Potential air temperature differences for different heights can therefore by calculated using

$$
\Gamma_{\theta(1.2-h)}=a \Gamma_{\theta(1.2-10)}-b v_{10}+c \theta^{*}-d \theta_{1.2}+e
$$

where

$$
\begin{aligned}
a & =-0.0994 \ln (h)+1.4208 \\
b\left(\mathrm{~s} \mathrm{~m}^{-1}\right) & =-0.0326 \ln (h)+0.0467 \\
c & =0.4531 \ln (h)-0.7131 \\
d\left(\mathrm{~K}^{-1}\right) & =-0.0546 \ln (h)+0.1167 \\
e & =16.394 \ln (h)-35.571
\end{aligned}
$$

Fig. 10 exemplifies the vertical profile of measured and calculated potential air temperatures during stable atmospheric layering near the ground. The examples show that the multiple-regression analysis based on the chosen independent variables is well suited to reproduce the thermal atmospheric layering during stable conditions. The largest errors at the higher levels still occur during largely positive lapse rates at the bottom levels. Other uncertainties are due to unstable layers overlying shallow near-ground inversion layers, e.g. in the summer morning and summer afternoon examples. Additional analyses of these cases could lead to a further decrease in the errors, but they would also increase model complexity.

\subsubsection{Unstable atmospheric layering near the ground}

Unstable atmospheric layering for this purpose will be defined by negative potential air temperature differences between the 1.2 and $10 \mathrm{~m}$ levels $\left(\theta_{10}-\theta_{1.2}<0\right)$. Table 5 shows cross tables of correlation coefficients for potential air temperature difference between 1.2 and
$96 \mathrm{~m}$ based on various parameters which were considered to be relevant for the multiple regression.

It can be seen that $\theta^{*}$ and $v_{10}$ are very weakly correlated to the differences (absolute correlation coefficients $<0.1)$. Therefore, only the variables $\Gamma_{\theta(1.2-10)}$ and $\theta_{1.2}$ will be included in the multiple regression. Multiple-regression analysis with inclusion of relevant variables yields

$$
\begin{aligned}
& \Gamma_{\theta(1.2-20)}=0.117 \Gamma_{\theta(1.2-10)}-0.0691 \theta_{1.2}+18.398 \\
& \Gamma_{\theta(1.2-40)}=0.117 \Gamma_{\theta(1.2-10)}-0.0819 \theta_{1.2}+22.117 \\
& \Gamma_{\theta(1.2-65)}=0.117 \Gamma_{\theta(1.2-10)}-0.0708 \theta_{1.2}+19.229 \\
& \Gamma_{\theta(1.2-96)}=0.106 \Gamma_{\theta(1.2-10)}-0.0839 \theta_{1.2}+23.302
\end{aligned}
$$

Table 6 shows that the multiple regression provides better results than the undifferentiated linear regression only for the higher levels. However, no improvement was achieved for the calculation of potential air temperatures at the lower levels. A differentiation between cases with an absolute error in the calculation of $\Gamma_{\theta(1.2-96)}$ greater or smaller than $1^{\circ} \mathrm{C}$ was made for a

Table 5. Pearson correlation coefficient for various factors during unstable atmospheric layering near ground (see Table 3 for explanation of parameters)

\begin{tabular}{|lrrrrr|}
\hline & $\Gamma_{\theta(1.2-96)}$ & $\theta_{1.2}$ & \multicolumn{1}{c}{$\theta^{*}$} & $V_{10}$ & $\Gamma_{\theta(1.2-10)}$ \\
\hline$\Gamma_{\theta(1.2-96)}$ & 1.000 & -0.434 & 0.026 & 0.020 & 0.244 \\
$\theta_{1.2}$ & & 1.000 & -0.014 & -0.149 & -0.063 \\
$\theta^{*}$ & & & 1.000 & 0.054 & 0.010 \\
$V_{10}$ & & & & 1.000 & 0.068 \\
$\Gamma_{\theta(1.2-10)}$ & & & & & 1.000 \\
\hline
\end{tabular}



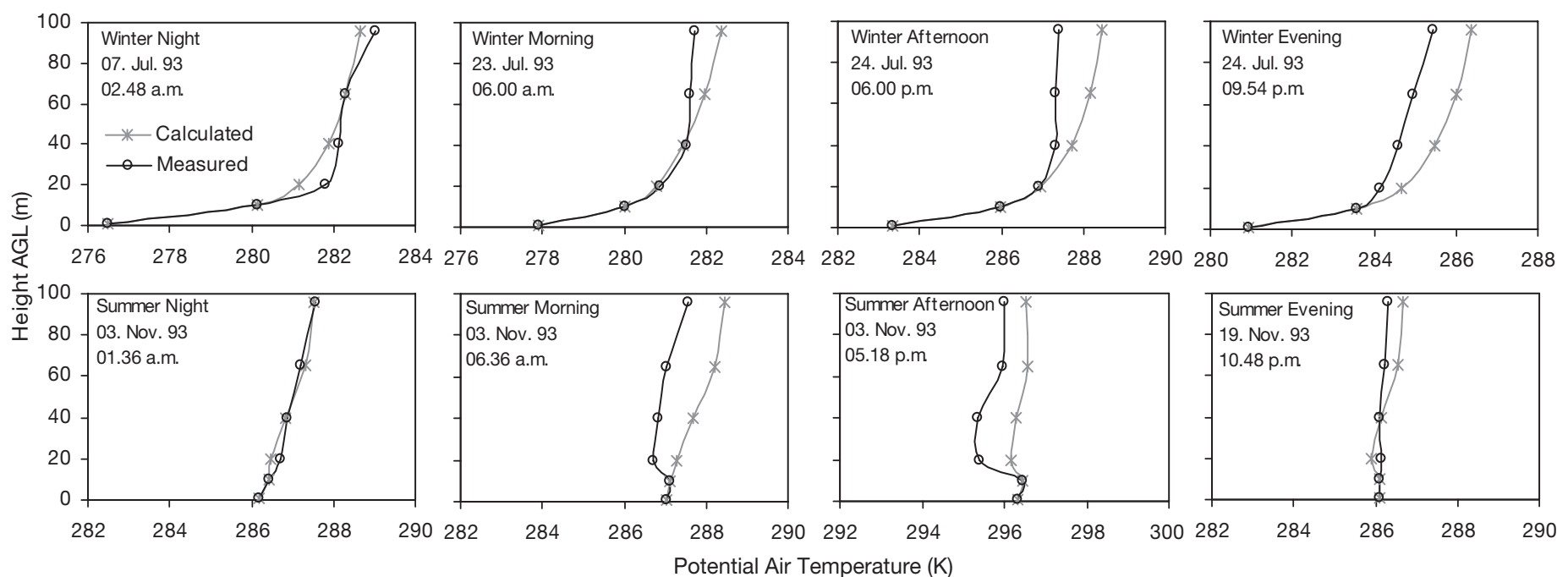

Fig. 10. Vertical profile of measured and calculated potential air temperatures during stable atmospheric layering near ground

further investigation. Averages and deviations for the 2 groups regarding various parameters are listed in Table 7 .

The potential temperature scale $\left(\theta^{*}\right)$, the MoninObukhov length $(L)$, the bottom level difference $\left(\Gamma_{\theta(1.2-10)}\right)$ and the precedent difference $\left(\Gamma_{\theta(1.2-96)}\right)$ take on absolutely higher values and the wind speed a slightly lower value for the larger error group. No considerable differences can be seen for the other parameter averages. Many parameters show a higher variability (standard deviation) for the large error group. These findings support the hypothesis that larger errors occurred in the early morning or late afternoon, with strong lapse rates at ground level and rapidly changing conditions.

Another aspect becomes apparent in Fig. 11. The left graph shows the number of cases with unstable thermal layering based on the differences of potential air temperatures at ground levels. Considerable numbers occur from 06:00/07:00 $\mathrm{h}$ in the morning to 16:00/17:00 $\mathrm{h}$ in the afternoon. The right graphs display the percentage of cases with calculation errors $>1$

Table 6. Mean deviation of measured and calculated potential air temperature differences based on the multiple linear regression functions or unstable atmospheric layering near ground

\begin{tabular}{|c|c|c|c|c|c|c|}
\hline & \multirow{2}{*}{$\left({ }^{\circ} \mathrm{C}\right)$} & \multicolumn{2}{|c|}{ Mean } & \multicolumn{2}{|c|}{ Quantile $\left({ }^{\circ} \mathrm{C}\right)$} & \multirow{2}{*}{$\begin{array}{c}\text { Median } \\
\left({ }^{\circ} \mathrm{C}\right)\end{array}$} \\
\hline & & $\mathrm{SD}$ & $(\%)$ & $90 \%$ & $75 \%$ & \\
\hline$\Gamma_{\theta(1.2-20)}$ & 0.68 & 0.50 & 34.28 & 1.40 & 1.03 & 0.58 \\
\hline$\Gamma_{\theta(1.2-40)}$ & 0.72 & 0.54 & 35.67 & 1.47 & 1.07 & 0.61 \\
\hline$\Gamma_{\theta(1.2-65)}$ & 0.71 & 0.56 & 42.68 & 1.40 & 1.01 & 0.60 \\
\hline$\Gamma_{\theta(1.2-96)}$ & 0.75 & 0.61 & 53.15 & 1.51 & 1.03 & 0.62 \\
\hline
\end{tabular}

Table 7. Mean and standard deviations of various parameters, differentiated after $\Delta \Gamma_{\theta(1.2-96)}$ larger or smaller than $1^{\circ} \mathrm{C}$

\begin{tabular}{|c|c|c|c|c|}
\hline & \multicolumn{2}{|c|}{ Mean } & \multicolumn{2}{|c|}{ SD } \\
\hline & $\begin{array}{c}\Delta \Gamma_{\theta(1.2-96)} \\
>1\end{array}$ & $\begin{array}{c}\Delta \Gamma_{\theta(1.2-96)} \\
<1\end{array}$ & $\begin{array}{c}\Delta \Gamma_{\theta(1.2-96)} \\
>>1\end{array}$ & $\begin{array}{c}\Delta \Gamma_{\theta(1.2-96)} \\
<1\end{array}$ \\
\hline$\theta^{*}$ & -5.11 & -3.29 & 105.89 & 91.46 \\
\hline$L(\mathrm{~m})$ & -241.10 & -168.34 & 3413.07 & 3859.74 \\
\hline$v_{10}\left(\mathrm{~m} \mathrm{~s}^{-1}\right)$ & 2.68 & 2.99 & 1.51 & 1.53 \\
\hline$\Gamma_{\theta(1.2-10)}(\mathrm{K})$ & -1.40 & -1.03 & 1.09 & 0.66 \\
\hline$\Gamma_{\theta(1.2-20)}(\mathrm{K})$ & -2.09 & -1.95 & 1.31 & 0.88 \\
\hline$\Gamma_{\theta(1.2-40)}(\mathrm{K})$ & -2.07 & -2.02 & 1.49 & 0.90 \\
\hline$\Gamma_{\theta(1.2-65)}(\mathrm{K})$ & -1.64 & -1.60 & 1.60 & 0.79 \\
\hline$\Gamma_{\theta(1.2-96)}(\mathrm{K})$ & -1.41 & -1.41 & 1.82 & 0.76 \\
\hline $\begin{array}{l}\text { Precedent } \\
\Gamma_{\theta(1.2-96)}(\mathrm{K})\end{array}$ & 0.38 & 0.26 & 5.07 & 1.30 \\
\hline
\end{tabular}

and $2{ }^{\circ} \mathrm{C}$. The probability of larger errors takes on the highest values during the early morning and towards the late afternoon, whereby the values from 18:00 to 05:00 h only refer to a comparatively small absolute number of cases. The critical cases are therefore obviously from $06: 00$ to $09: 00 \mathrm{~h}$ and from $16: 00$ to $17: 00 \mathrm{~h}$, whereas calculation for the noontime appear to be more accurate.

The reason for this could be that convective heat transfer does not reach higher regions of the boundary layer during times of relatively weak insolation. Therefore it is meaningful to address this problem by introducing another variable such as the solar angle as an external factor for the calculations. The implementation of the solar angle as an independent variable in the multiple regression did not improve the results; however, a distinction of cases with solar angles larger 

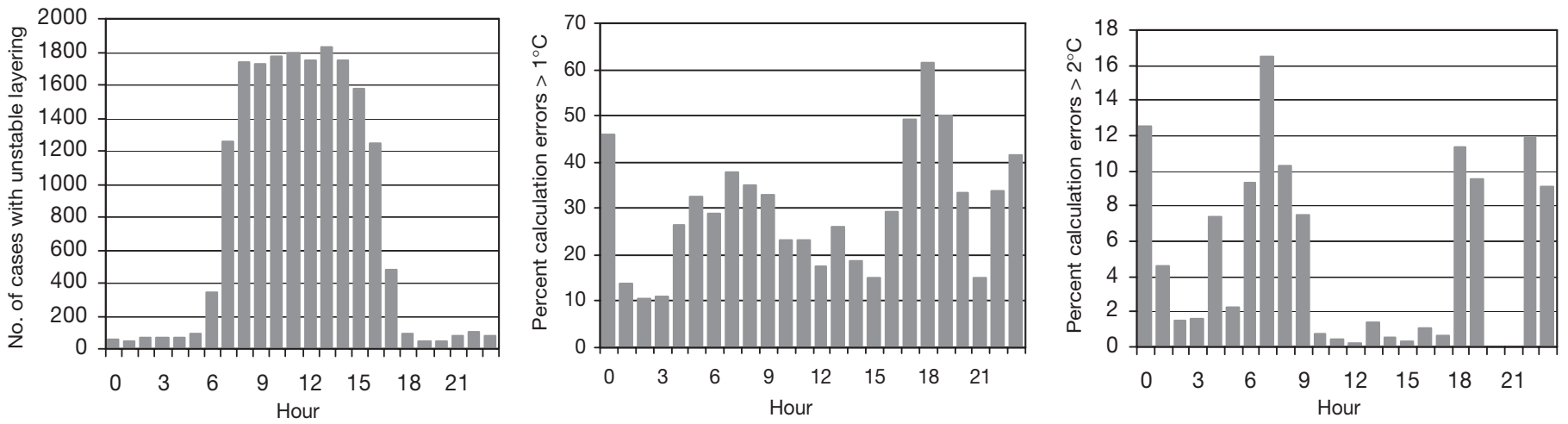

Fig. 11. Left graph: absolute number of cases with thermal instability; right graphs: percentage of cases with large errors $\left(>1^{\circ} \mathrm{C}\right.$ center, $>2^{\circ} \mathrm{C}$ far right) in relation to the number of cases with instability at that particular time

or smaller than $20^{\circ}$ with a subsequent implementation led to a considerable decrease in the calculation errors. It was meaningful with regard to minimizing the errors of the approach to re-introduce the wind speed at $10 \mathrm{~m}$ as an independent variable after the subdivision of the dataset into the 2 groups.

Linear multiple regression analysis for the 14744 cases with solar angles $(\gamma)>20^{\circ}$ yielded the following algorithms:

$\Gamma_{\theta(1.2-20)}=0.940 \Gamma_{\theta(1.2-10)}+0.0013 v_{10}-0.0362 \theta_{1.2}+0.00154 \gamma+9.530$

$\Gamma_{\theta(1.2-40)}=0.940 \Gamma_{\theta(1.2-10)}-0.0199 v_{10}-0.0402 \theta_{1.2}+0.00040 \gamma+10.719$

$\Gamma_{\theta(1.2-65)}=0.985 \Gamma_{\theta(1.2-10)}-0.0708 v_{10}-0.0243 \theta_{1.2}-0.00189 \gamma+6.779$

$\Gamma_{\theta(1.2-96)}=0.944 \Gamma_{\theta(1.2-10)}-0.1080 v_{10}-0.0308 \theta_{1.2}-0.00350 \gamma+9.019$

The scale parameters point to the fact that the solar angle as an independent variable does not contribute considerably to the calculation; however, it does serve

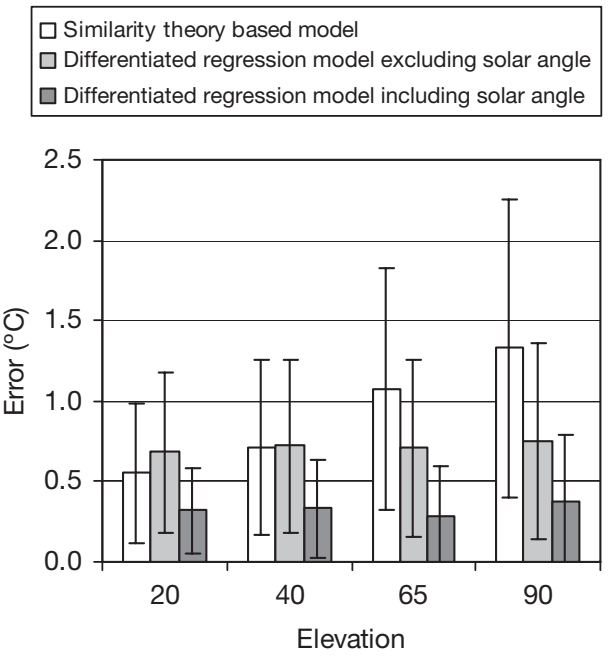

Fig. 12. Comparison of the errors of the different approaches to calculate air temperatures at different elevations (mean and standard deviations) as a suitable parameter to subdivide the dataset in a way that enables more accurate calculations based on the other variables.

Table 8 shows that considerable improvements in the accuracy were achieved by this differentiation.

Linear multiple regression analysis for the 3356 cases with solar angles $(\gamma)<20^{\circ}$ yielded the following algorithms:

$\Gamma_{\theta(1.2-20)}=0.976 \Gamma_{\theta(1.2-10)}+0.0166 v_{10}-0.0394 \theta_{1.2}+0.00700 \gamma+11.017$

$\Gamma_{\theta(1.2-40)}=0.948 \Gamma_{\theta(1.2-10)}-0.0118 v_{10}-0.0608 \theta_{1.2}-0.00595 \gamma+17.380$

$\Gamma_{\theta(1.2-65)}=0.906 \Gamma_{\theta(1.2-10)}-0.0558 v_{10}-0.0698 \theta_{1.2}-0.000292 \gamma+20.439$

$\Gamma_{\theta(1.2-96)}=0.776 \Gamma_{\theta(1.2-10)}-0.0708 v_{10}-0.0976 \theta_{1.2}+0.002885 \gamma+28.701$

It can be seen from Table 9 and Fig. 12 that the implementation of the solar angle in the calculation algorithms

Table 8. Mean deviation of measured and calculated potential air-temperature differences during unstable conditions with solar angle $>20^{\circ}$

\begin{tabular}{|cccccc|}
\hline & \multicolumn{2}{c}{ Mean } & \multicolumn{2}{c|}{ Quantile $\left({ }^{\circ} \mathrm{C}\right)$} & Median \\
& $\left({ }^{\circ} \mathrm{C}\right)$ & $\mathrm{SD}$ & $90 \%$ & $75 \%$ & $\left({ }^{\circ} \mathrm{C}\right)$ \\
\hline$\Delta \Gamma_{\theta(1.2-20)}$ & 0.32 & 0.25 & 0.68 & 0.46 & 0.27 \\
$\Delta \Gamma_{\theta(1.2-40)}$ & 0.34 & 0.28 & 0.72 & 0.48 & 0.28 \\
$\Delta \Gamma_{\theta(1.2-65)}$ & 0.28 & 0.26 & 0.57 & 0.39 & 0.22 \\
$\Delta \Gamma_{\theta(1.2-96)}$ & 0.37 & 0.36 & 0.75 & 0.50 & 0.28 \\
\hline
\end{tabular}

Table 9. Mean deviation of measured and calculated potential air-temperature differences during unstable conditions with solar angle $<20^{\circ}$

\begin{tabular}{|c|c|c|c|c|c|}
\hline & \multicolumn{2}{|c|}{ Mean } & \multicolumn{2}{|c|}{ Quantile $\left({ }^{\circ} \mathrm{C}\right)$} & \multirow{2}{*}{$\begin{array}{c}\text { Median } \\
\left({ }^{\circ} \mathrm{C}\right)\end{array}$} \\
\hline & $\left({ }^{\circ} \mathrm{C}\right)$ & $\mathrm{SD}$ & $90 \%$ & $75 \%$ & \\
\hline$\Gamma_{\theta(1.2-20)}$ & 0.39 & 0.32 & 0.80 & 0.54 & 0.32 \\
\hline$\Gamma_{\theta(1.2-40)}$ & 0.40 & 0.42 & 0.87 & 0.51 & 0.28 \\
\hline$\Gamma_{\theta(1.2-65)}$ & 0.47 & 0.54 & 1.07 & 0.58 & 0.31 \\
\hline$\Gamma_{\theta(1.2-96)}$ & 0.63 & 0.64 & 1.47 & 0.80 & 0.44 \\
\hline
\end{tabular}



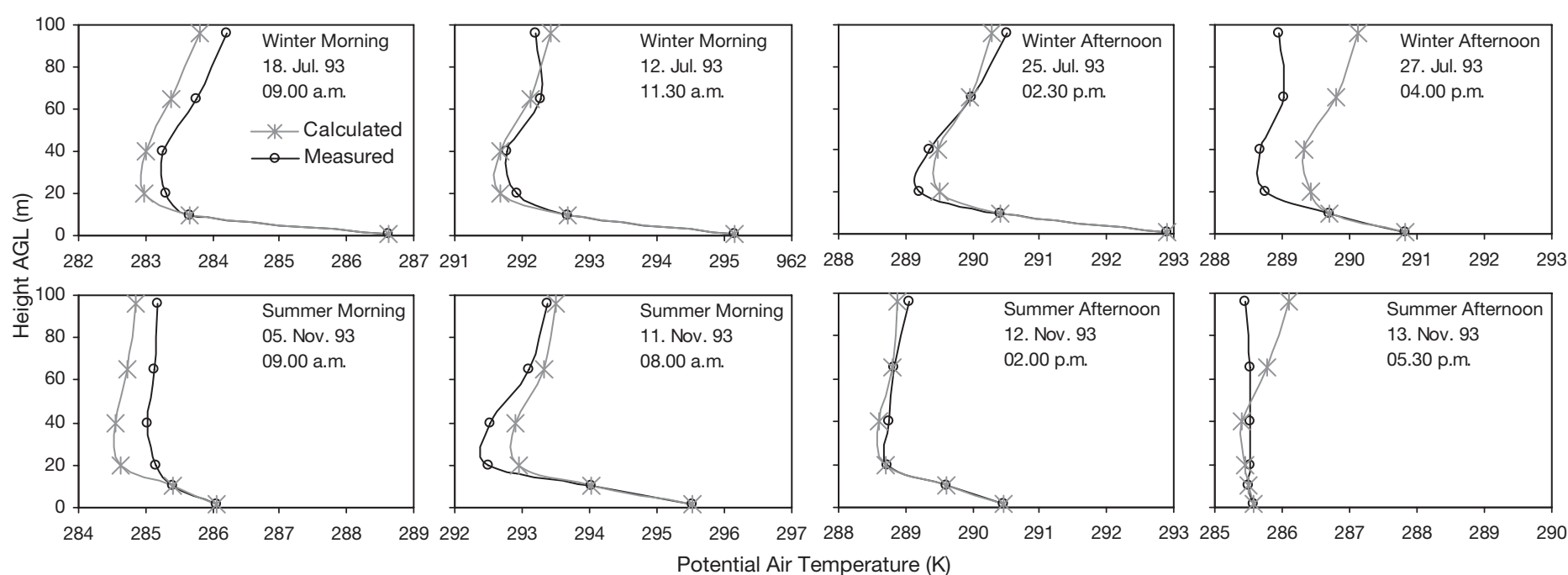

Fig. 13. Measured and calculated potential air temperatures during unstable conditions

resulted in considerably lower deviations of measured and calculated potential air-temperature differences. Fig. 12 shows that the differentiated regression model provides the most-accurate results for the calculation of air temperatures at levels up to $96 \mathrm{~m}$ AGL.

Fig. 13 illustrates the accuracy of the calculations on several days exhibiting unstable conditions.

\section{SUMMARY}

Thermal atmospheric boundary layering over the Mpumalanga Highveld shows distinctive characteristics with relatively deep stable conditions during the night and unstable conditions near the ground during daytime with inconsistent layering above. The calculation of the vertical thermal layering by similarity theory based models proved to be inadequate. Calculation of the vertical profile of potential air temperatures is achieved with improved accuracy up to $100 \mathrm{~m} \mathrm{AGL}$ by a multiple linear regression methodology based on the 4 independent variables (1) potential air temperature difference between 1 and $10 \mathrm{~m} \mathrm{AGL,} \mathrm{(2)} \mathrm{wind}$ speed, (3) potential air temperature at $1 \mathrm{~m}$ AGL and (4) solar angle.

Editorial responsibility: Otto Kinne, Oldendorf/Luhe, Germany
Acknowledgements. The author would like to thank Neil Snow at TSI, Rosherville, South Africa, Siven Naidoo at Eskom, Johannesburg, South Africa, and Gerhard Held (now at IPMET, Bauru, Brazil) for providing the data and supporting information.

\section{LITERATURE CITED}

Eskom (1994) Statistical yearbook for 1993. Eskom, Sandton, South Africa

Held G, Gore BJ, Surridge AD, Tosen GR, Turner CR, Walmsley RD (1996) Air pollution and its impacts on the South African Highveld. Environmental Scientific Association, Cleveland, South Africa

Jacobsen MZ (1999) Fundamentals of atmospheric modelling. Cambridge University Press, Cambridge

Louis JF (1979) A parametric model of vertical eddy fluxes in the atmosphere. Boundary Layer Meteorol 17:87-202

Monin AS, Obukhov AM (1954) The basic laws of the eddying motion in the lowest layer of the atmosphere. USSR Acad Sci Publ Geophys Inst No. 24:163

Oke TR (1987) Boundary layer climates. Methuen, London

Preston-Whyte RA, Tyson PD (1993) The atmosphere and weather of Southern Africa. Oxford University Press, London

Pichler H (1997) Dynamik der Atmosphäre. Spektrum Akademischer Verlag, Heidelberg

Roedel W (2000) Physik unserer Umwelt-die Atmosphäre. Springer-Verlag

Submitted: December 2, 2003; Accepted: April 6, 2005

Proofs received from author(s): August 18, 2005 